\title{
The Assessment of Relationship between Facial Morphology and Tongue Function During Swallowing - An Ultrasound Study
}

\author{
${ }^{1}$ Dr.Vaishnevi. N.T., ${ }^{2}$ Dr.Ajith Rajasekharan, ${ }^{3}$ Dr Aravind D, ${ }^{4}$ Dr Ajay Kumar \\ Pillai, ${ }^{5}$ Dr. Swipnil Moghe., ${ }^{6}$ Dr.Trilokshrivastava, \\ ${ }^{1}$ Lecturer,Faculty of Dentistry Segi University,Delangor, Malaysia \\ ${ }^{2}$ Reader ,Dept. of Orthodontics, Azeezia dental college, Kollam,Kerala. \\ ${ }^{3}$ Post gradaute,Dept. of Orthodontics, Azeezia dental college, Kollam, Kerala. \\ ${ }^{4}$ Reader, Dept. of Oral And Maxillo Facial Surgery.PDA,Peoples University Bhopal \\ ${ }^{5}$ Dept. of Oral And Maxillo Facial Surgery.PDA,Peoples University Bhopal \\ ${ }^{6}$ Reader, Dept. of OrthodonticsPDA,Peoples University Bhopal
}

\begin{abstract}
:
Introduction: To study the tongue movement during swallowing and assess the relationship between tongue movement and facial morphology in three types of malocclusion.

Materials and methods: 30 volunteers with class I, class II and class III skeletal pattern were chosen. The skeletal pattern was assessed from lateral cephalogram. B+M mode ultrasonography with cushion scanning technique was used to study the tongue movement during swallowing. The motion magnitude, duration and speed of tongue movement during each phase of swallowing were obtained from the m-mode graph and the representative values used for statistical analysis.

Results: The individuals with class III skeletal pattern (prognathic mandible) had prolonged duration of tongue movement and greater motion magnitude in the early final phase (III A) of swallowing. Though there was a decrease in the motion magnitude and duration of swallowing in the early final phase in the individuals with class II skeletal pattern, the difference between class I and class II skeletal pattern was not found to be statistically significant. There was no significant difference in the speed of swallowing between the three skeletal patterns.

Conclusion: More correlation was found to exist between abnormal tongue function during swallowing and class III skeletal pattern than the class I and class II skeletal patterns.
\end{abstract}

Key words: malocclusion, swallowing, tongue movement, ultrasonography

\section{Introduction}

Since the dawn of the 20th century when orthodontics was developing as dentistry's first speciality, orthodontists have felt that there is a close association between the tongue and different malocclusions. However its role in causing malocclusion has never been conclusively proved.

The form and function are intimately related. According to Balters, the tongue is the centre of reflex activity in the oral cavity and its position must be considered carefully in planning treatment. He believed that discoordination of tongue's function would lead to abnormal growth and actual deformation. He has pointed out that a posterior displacement of the tongue would lead to class II malocclusion and a low anterior displacement of the tongue would lead to class III malocclusion ${ }^{1}$. Therefore the dental professionals must be able to identify abnormal tongue postures and movements that might have adverse effect on dentofacial growth and treatment. The altered tongue function can lead to increased relapse after orthodontic treatment.

In the past, examination of the tongue's motor function was restricted to pure clinical observation. To date diagnostic aids like electropalatography, cineradiology, computed tomography, magnetic resonance imaging, electromagnetic articulography and ultrasonography ${ }^{2-22}$ were used. Electropalatography and electromagnetic articulography are not suitable for studying tongue function because it is difficult for the subjects to swallow normally with receiver coils and wires attached to their palate and tongue. X-ray cinematography and computed tomography have disadvantages of radiation exposure. Magnetic resonance imaging is not suitable for examining swallowing movements because of its high cost and long acquisition time. Ultrasonography has the advantages of being noninvasive, rapid, repeatable and relatively inexpensive ${ }^{2}$.

The purpose of the present study was to study the movement of the tongue during swallowing in three types of malocclusion and to assess the relationship between tongue movement and facial morphology. 


\section{Materials And Methods}

A total number of thirty volunteers, 10 in each with class I, class II and class III skeletal pattern were chosen from the students at the V.M.S dental college and the V.M.K.V medical college, patients in the department of orthodontics of the V.M.S dental college, nursing staff at the SISU hospitals, nursing students at the Shanmuga institutions and hospitals. Informed consent was obtained from all volunteers after brief description of the aim and nature of the study.

Patients included in the study were under 30 years. The class I skeletal pattern should have normal ANB angle and Wits appraisal. The class II skeletal pattern should have orthognathic maxilla, retrognathic mandible, increased ANB angle and Wits appraisal. The class III skeletal pattern should have orthognathic maxilla, prognathic mandible, reduced ANB angle and Wits appraisal (Fig 1,2,3). Patients with history of previous orthodontic treatment, missing teeth, facial asymmetry, signs of dysphagia and tongue functional disorders were excluded from the study. The skeletal pattern is assessed from lateral cephalogram using ANB angle and Wit's appraisal.

Fig 1: Profile Photograph and lateral cephalogram of patient with Skeletal Class I

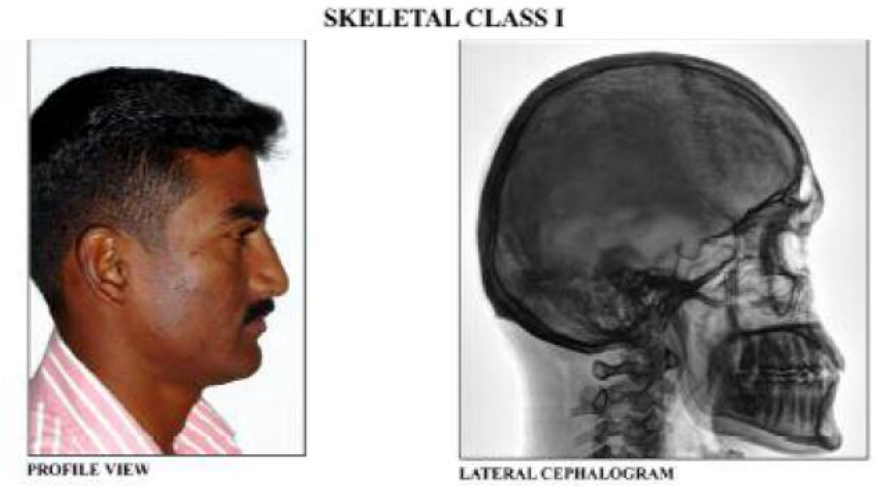

Fig 2: Profile Photograph and lateral cephalogram of patient with Skeletal Class II

SKELETAL CLASS II
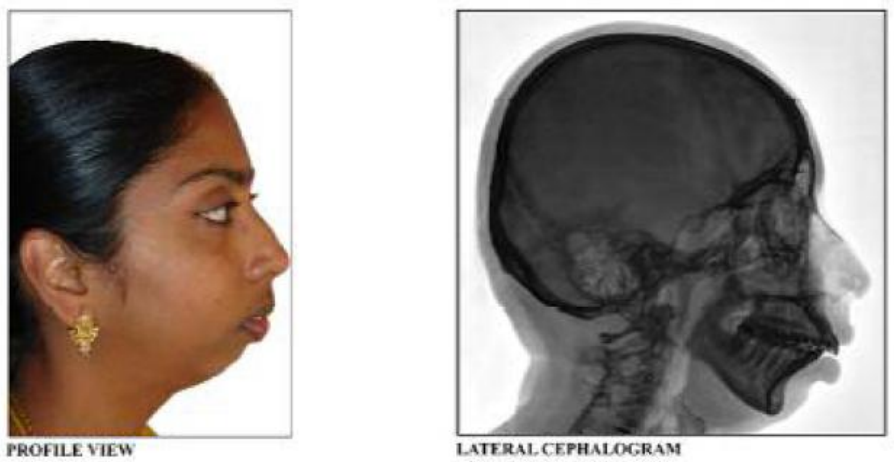

Fig 3: Profile Photograph and lateral cephalogram of patient with Skeletal Class III

SKELETAL CLASS III
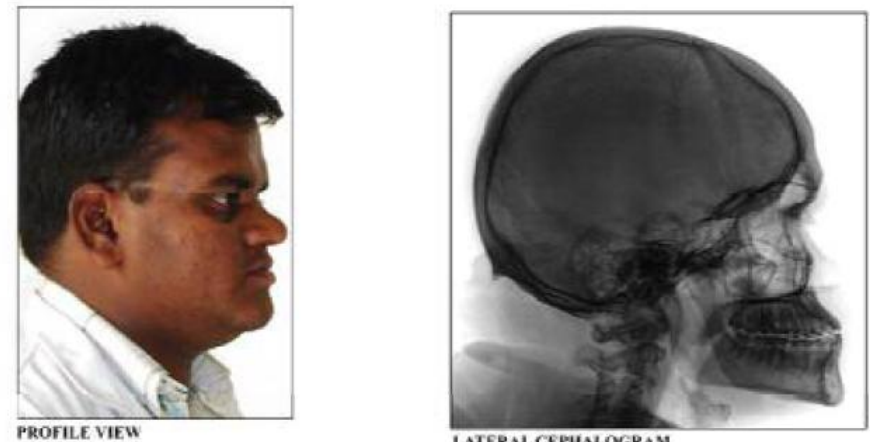

LATERALCEPHALOGRAM 
Colour Doppler ultrasound machine (WIPRO GE LOGIC 400) (Fig 4,5) in combination with CST (cushion scanning technique) in which $500 \mathrm{ml}$ PVC bag filled with water is used as cushion. The bag creates a buffer area between the transducer and the skin to avoid problems such as the movement of ultrasound transducer during swallowing and the compression of the submental region. It also has a holder [with adjustable hinges] with scales for fixing the ultrasound transducer and to allow for reproducible registration of different scanning directions and a head support.

Fig 4. Colour Doppler Ultrasound machine.

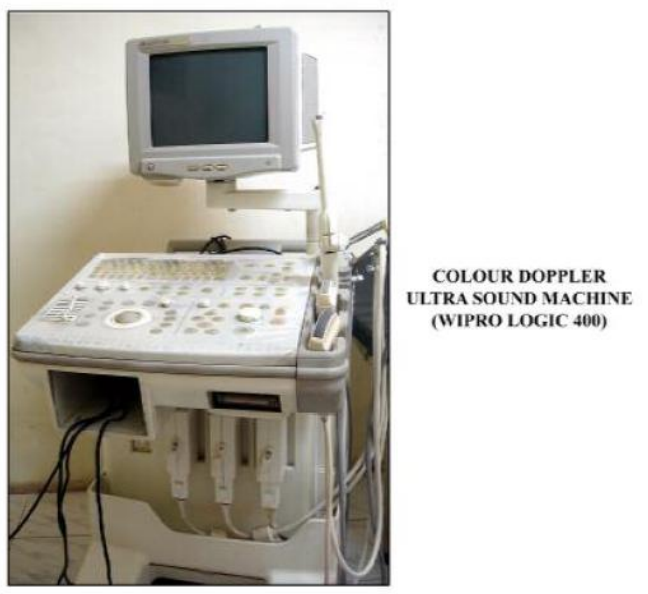

Fig 5: Cushion Scanning Technique with transducer

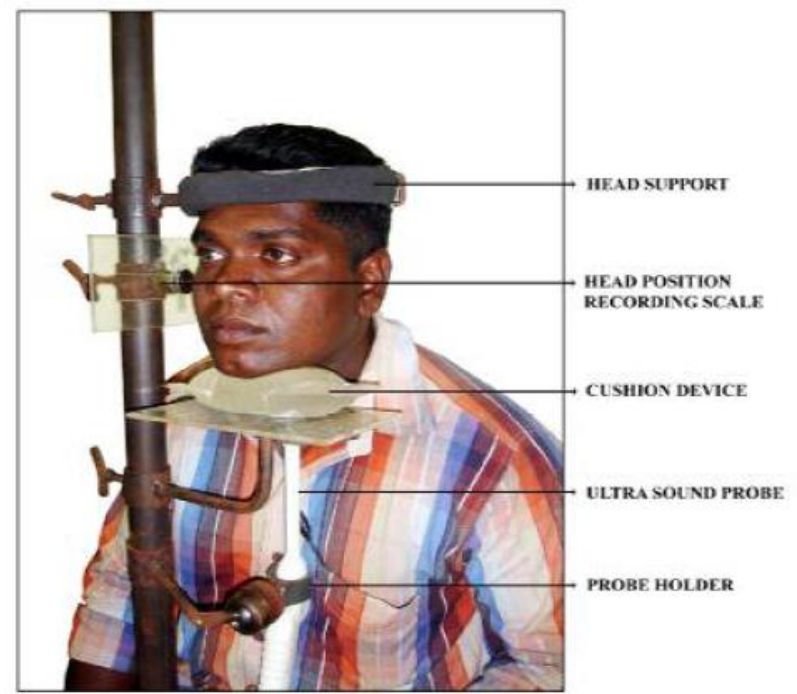

Swallowing is studied with B+M mode sonography with CST. To initiate wet swallowing (habitual swallow), the participants were asked to swallow $3-5 \mathrm{ml}$ of water before ultrasound registration, wait for 10 seconds and then swallow again. Each swallowing cycle is repeated 3 times with 20 second interval.

The transducer is placed midway between the posterior border of symphysis and the anterior border of the hyoid bone in the midsagittal plane and oriented with long axis perpendicular to FH plane. The gel is applied to all coupling surfaces. The scan line [zero M position] was placed through the middle of the B-mode sector image. The corresponding graph for the scan line placed in the zero M- position is obtained in the M- mode. The quantitative assessment of swallowing is done in the M-mode (Fig 6,7,8). 
Fig 6. Qualitative assessment of B+M mode ultra sonogram with class I skeletal patient

\section{B + M MODE ULTRA SONOGRAM}

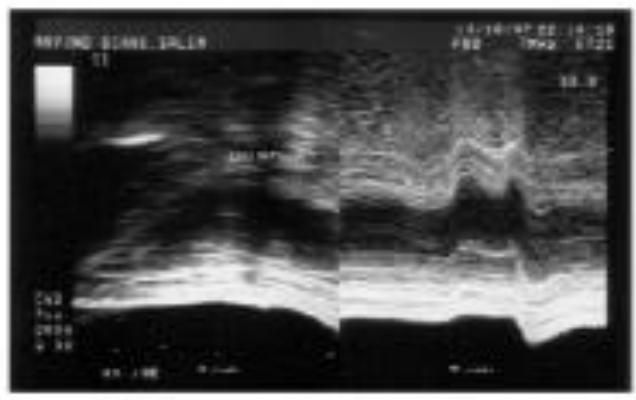

SKELETAL CLASS I

Fig 7. Qualitative assessment of B+M mode ultra sonogram with class II skeletal patient

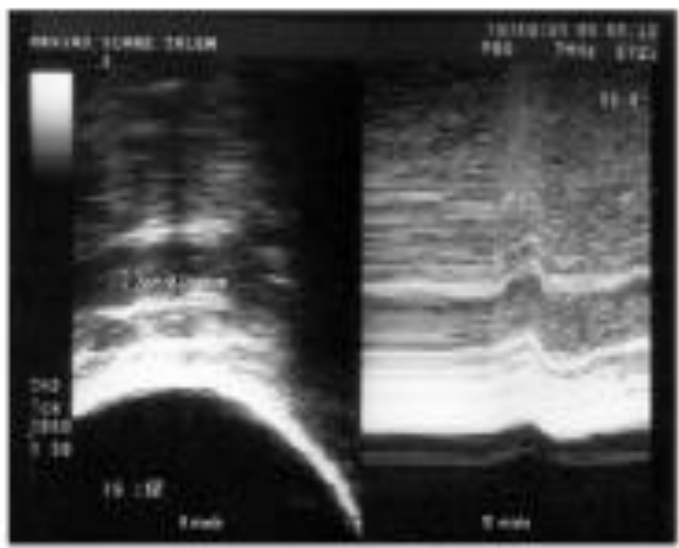

SKELETAL CLASS II

Fig 8. Qualitative assessment of B+M mode ultra sonogram with class III skeletal patient

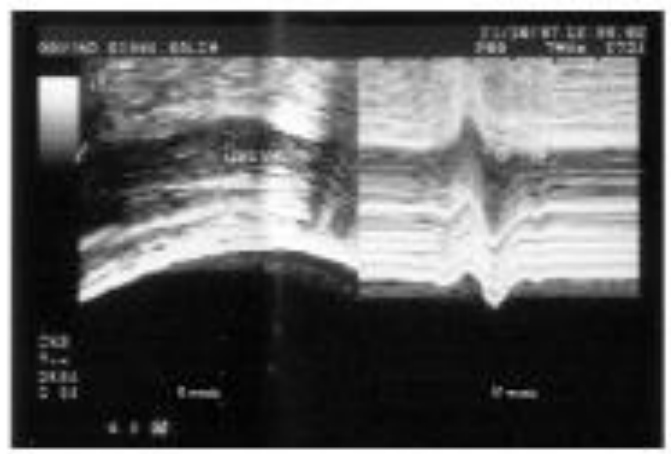

SKELETAL CLASS III

The swallowing pattern obtained was divided into three phases of swallowing along each turn point of the graphic M-mode image (Fig 9). Phase I is shovel phase, phase II is transport phase and phase III is final phase. Phase II further divided into Early (IIa) and Late (IIb) phases. Phase III divided into Ealy (IIIa) and late (IIIb). Totally five different phases were studied. The motion magnitude, duration and speed of tongue movement during each phase of swallowing were obtained. The mean of each swallowing cycle was used as the representative value for statistical analysis. 
Fig 9.The M Mode graph during various swallowing phases.Phase I is showel phase, Phase IIa is early transport phase, Phase IIb is late transport phase, Phase IIIa is warly final phase and Phase IIIb is late final phase.

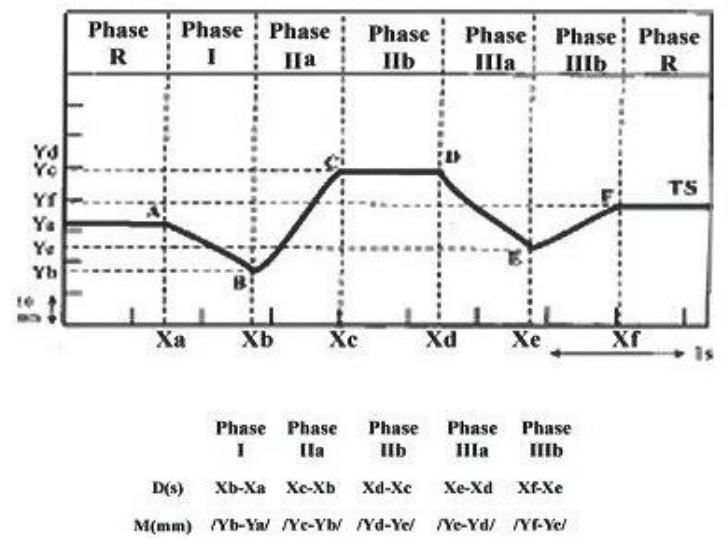

\section{Statistical Method}

The relationship between the facial morphology and tongue movement in the five different phases of swallowing was analyzed with ANOVA. The test for mean score analysis, the analysis of variance (ANOVA) test procedure was used to compare mean scores of level of satisfaction for more than two groups. The procedure assumes that the variances of the groups (skeletal patterns) in each phase of tongue movement were equal and it was tested with Levene's test statistics. The significant difference between the mean scores of level of satisfaction was tested and the results obtained.

\section{Results}

The results are presented in the five different phases of swallowing in which the study was conducted. The descriptive statistics of the mean and standard deviations and standard error of the ultrasound measurement of the motion magnitude, duration and speed of tongue movement during the five different phases of swallowing in 30 individuals with class I, class II and class III skeletal patterns is shown in the table $\mathbf{1}$.

The test for mean values and standard deviation were tested with ANOVA test procedures and the results of the analysis are given in the table 2. The tables show the F statistics, calculated as the ratio of variances and the probability value from the $\mathrm{F}$ distribution.

Null hypothesis: H0: There is no significant difference in the duration, magnitude and speed of the tongue movement during the five phases of swallowing between the three skeletal patterns.

Since the $\mathrm{p}$ value for the duration, magnitude and speed of the tongue movement in the shovel, early transport, late transport, and late final phases of swallowing is more than 0.05 , we accept the hypothesis. Hence there is no significant difference in the duration, magnitude and speed of the tongue movement during these four phases of swallowing between the three skeletal patterns.

Since the $\mathrm{p}$ value for the duration and magnitude of the tongue movement in the early final phase is less than 0.05 , the hypothesis was not accepted. Here, there is significant difference in the mean scores of magnitude and duration of the tongue movement during swallowing in this phase between the three skeletal patterns. There is no significant difference in the mean scores of the speed of tongue movement during swallowing in this phase between the three skeletal patterns.

Once we have determined that differences exist among the means of the magnitude and duration among the three types of skeletal patterns, post hoc range tests were used to determine which mean differ. Turkey's test was used to identify the homogenous subsets of means that are not different from each other. They show that the magnitude and duration respectively of swallowing in class I and class II group in this phase do not significantly differ from each other but these groups differ significantly from the class III group. The comparison graphs show the difference in the motion magnitude, duration and speed of swallowing in the all five phases (Graph $1,2,3)$. 
Table 1. One way descriptive statistical analysis of the ultrasound measurement of the motion magnitude, duration and speed of tongue movement during the five different phases of swallowing in class I, class II and class III skeletal patterns

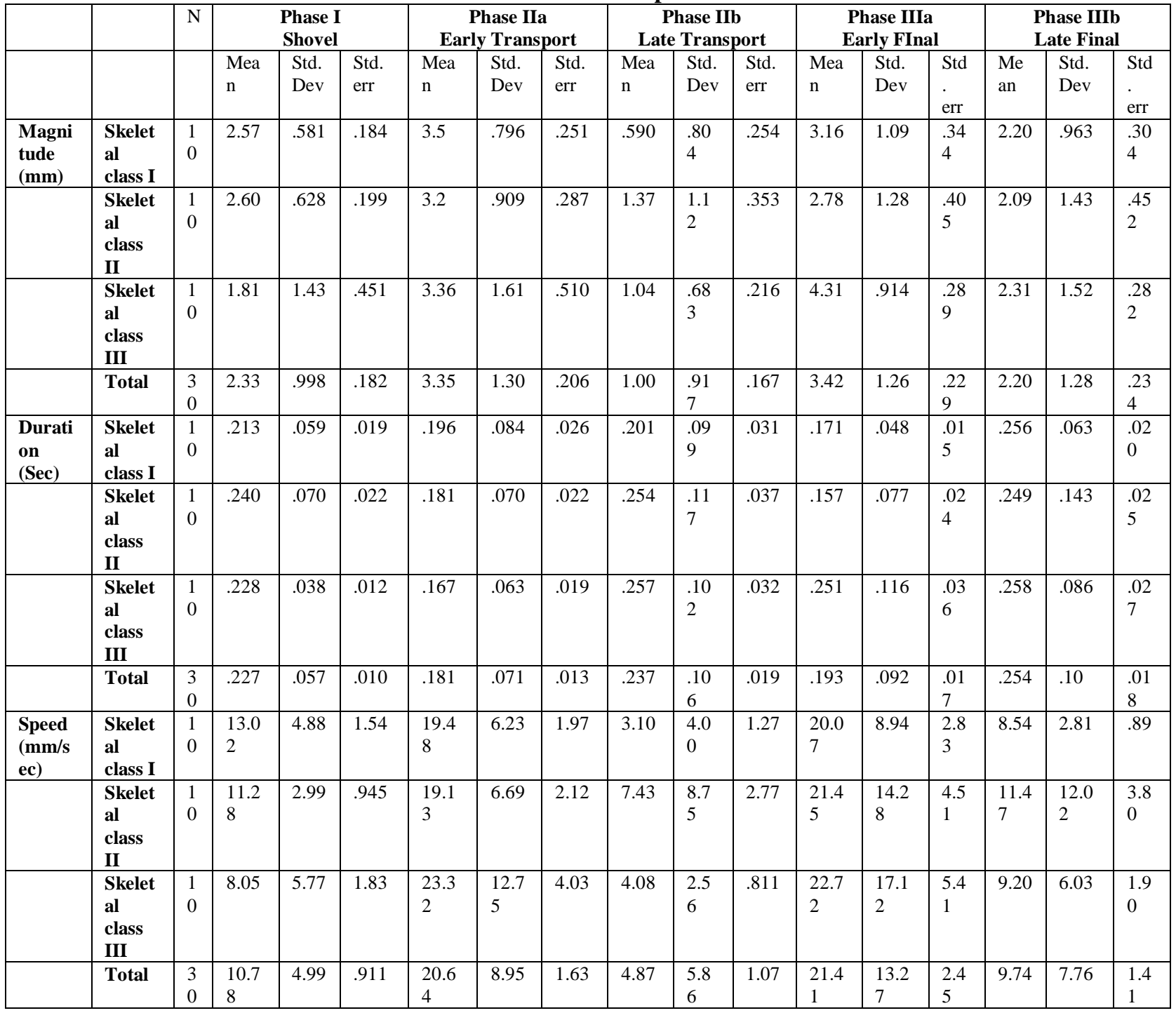

Table 2. Comparisons of the ultrasound measurement of the motion magnitude, duration and speed of tongue movement during the five different phases of swallowing in all 3 groups

\begin{tabular}{|c|c|c|c|c|c|c|}
\hline \multicolumn{7}{|c|}{ Phase I- Shovel phase } \\
\hline & & Sum of squares & Df & Mean square & $\mathrm{F}$ & Sig. \\
\hline \multirow[t]{3}{*}{ Magnitude } & Between Groups & 4.009 & 2 & 2.004 & 2.173 & .133 \\
\hline & Within Groups & 24.910 & 27 & .923 & & \\
\hline & Total & 28.919 & 29 & & & \\
\hline \multirow[t]{3}{*}{ Duration } & Between Groups & .004 & 2 & .002 & .549 & .584 \\
\hline & Within Groups & .090 & 27 & .003 & & \\
\hline & Total & .094 & 29 & & & \\
\hline \multirow[t]{3}{*}{ Speed } & Between Groups & 127.071 & 2 & 63.535 & 2.885 & .073 \\
\hline & Within Groups & 594.601 & 27 & 22.022 & & \\
\hline & Total & 721.672 & 29 & & & \\
\hline \multicolumn{7}{|c|}{ Phase IIa- Early Transport phase } \\
\hline \multirow[t]{3}{*}{ Magnitude } & Between Groups & .451 & 2 & .225 & .166 & .848 \\
\hline & Within Groups & 36.604 & 27 & 1.356 & & \\
\hline & Total & 37.055 & 29 & & & \\
\hline \multirow[t]{3}{*}{ Duration } & Between Groups & .004 & 2 & .002 & .397 & .676 \\
\hline & Within Groups & .143 & 27 & .005 & & \\
\hline & Total & .147 & 29 & & & \\
\hline \multirow[t]{3}{*}{ Speed } & Between Groups & 107.823 & 2 & 53.911 & .657 & .526 \\
\hline & Within Groups & 2214.961 & 27 & 82.036 & & \\
\hline & Total & 2322.783 & 29 & & & \\
\hline
\end{tabular}


The Assessment of Relationship between Facial Morphology and Tongue Function During

\begin{tabular}{|c|c|c|c|c|c|c|}
\hline \multicolumn{7}{|c|}{ Phase IIb- Late Transport phase } \\
\hline \multirow[t]{3}{*}{ Magnitude } & Between Groups & 3.066 & 2 & 1.533 & 1.944 & .163 \\
\hline & Within Groups & 21.294 & 27 & .789 & & \\
\hline & Total & 24.360 & 29 & & & \\
\hline \multirow[t]{3}{*}{ Duration } & Between Groups & .020 & 2 & .010 & .876 & .428 \\
\hline & Within Groups & .306 & 27 & .011 & & \\
\hline & Total & .326 & 29 & & & \\
\hline \multirow[t]{3}{*}{ Speed } & Between Groups & 103.078 & 2 & 51.539 & 1.559 & .229 \\
\hline & Within Groups & 892.828 & 27 & 33.068 & & \\
\hline & Total & 995.906 & 29 & & & \\
\hline \multicolumn{7}{|c|}{ Phase IIIa- Early Final phase } \\
\hline \multirow[t]{3}{*}{ Magnitude } & Between Groups & 12.693 & 2 & 6.346 & 5.188 & .012 \\
\hline & Within Groups & 33.029 & 27 & 1.223 & & \\
\hline & Total & 45.722 & 29 & & & \\
\hline \multirow[t]{3}{*}{ Duration } & Between Groups & .051 & 2 & .026 & 3.558 & .043 \\
\hline & Within Groups & .195 & 27 & .007 & & \\
\hline & Total & .247 & 29 & & & \\
\hline \multirow[t]{3}{*}{ Speed } & Between Groups & 35.208 & 2 & 17.604 & .092 & .913 \\
\hline & Within Groups & 5192.208 & 27 & 192.304 & & \\
\hline & Total & 5227.415 & 29 & & & \\
\hline \multicolumn{7}{|c|}{ Phase IIIb- Late Final phase } \\
\hline \multirow[t]{3}{*}{ Magnitude } & Between Groups & 242 & 2 & .121 & .069 & .934 \\
\hline & Within Groups & 47.578 & 27 & 1.762 & & \\
\hline & Total & 47.820 & 29 & & & \\
\hline \multirow[t]{3}{*}{ Duration } & Between Groups & .000 & 2 & .000 & .020 & .980 \\
\hline & Within Groups & .287 & 27 & .011 & & \\
\hline & Total & .288 & 29 & & & \\
\hline \multirow[t]{3}{*}{ Speed } & Between Groups & 47.282 & 2 & 23.641 & .376 & .690 \\
\hline & Within Groups & 1699.394 & 27 & 62.941 & & \\
\hline & Total & 1746.676 & 29 & & & \\
\hline
\end{tabular}

Graph 1: Comparison of the motion magnitude of swallowing in class I, Class II and Class III skeletal patients in all 5 phases

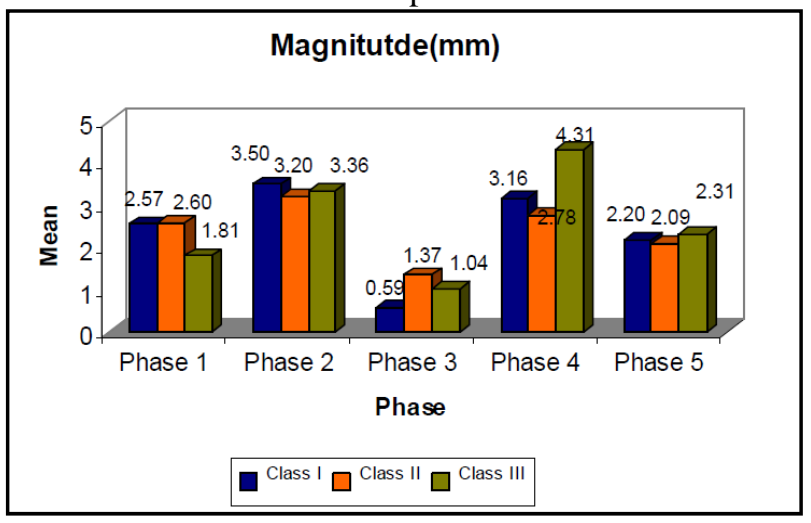

Graph 2. Comparison of the duration of swallowing magnitude of swallowing in class I, Class II and Class III skeletal patients in all 5 phases.

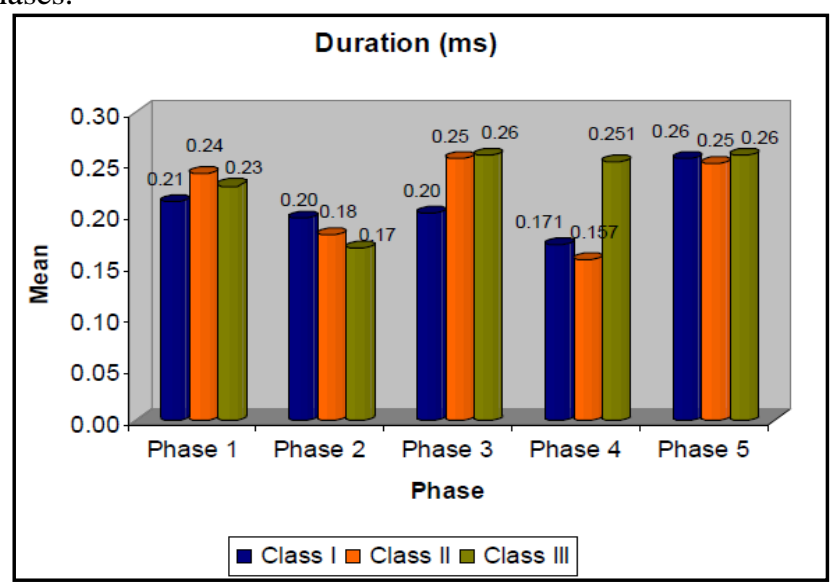


Graph 3. Comparison of the speed of swallowing magnitude of swallowing in class I, Class II and Class III skeletal patients in all 5 phases

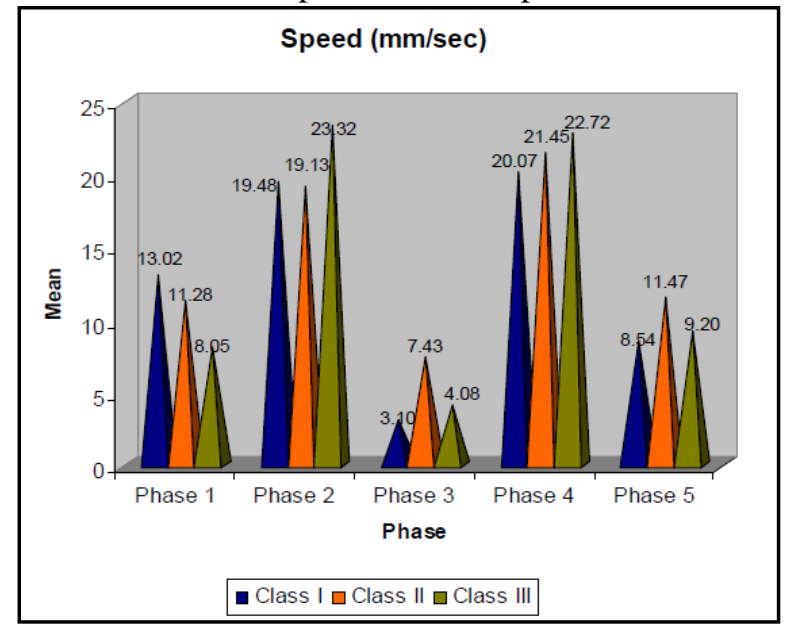

\section{Discussion}

It is paramount for orthodontists to understand the relationship between tongue function and facial morphology. Significant percentage of relapse after orthodontic treatment might be related to orofacial muscle imbalance and abnormal swallowing.

Ultrasonography has been used in many studies for static imaging of the oral cavity (eg. for studying tongue morphology and for diagnosing sialolithiasis, tumours). Dynamic ultrasound investigation of tongue movement through submental scanning has been described by many researchers to evaluate the tongue during speech and swallowing.

Akiyoshiet $\mathrm{al}^{3}$ showed that swallowing saliva, consciously or unconsciously, is much more frequent than swallowing during drinking and eating. A normal adult repeats this normal swallowing pattern between 1200 and 3000 times every day. Therefore habitual swallowing of saliva was considered to have more effect on dentofacial morphology than water swallowing and was chosen in the present study.

B - modeSonography was commonly used in the past to determine the duration of swallowing sonographically and to analyze B-mode recordings of tongue movement frame by frame. This method was first used by Shawkeret $\mathrm{al}^{4}$ to show the tongue in speech assessment and neurological diagnosis. The definitions of the start and the end of tongue movements were somewhat arbitrary, especially if no superimpositions of consecutive frames were used.

Previous ultrasonographic studies on tongue functions were limited by the possibility of artifacts caused by movement of the submental area during function due to the direct transducer skin coupling scanning. This resulted in the inaccurate measurement of the tongue movements. With a cushion scanning technique (CST) that consists of a cushion device, a head support, an ultrasound transducer holder, and a head position recording device, the dynamic tongue activity can be correctly recorded and measured. It has been proven to create a buffer area between the transducer and the skin to avoid problems such as the movement of ultrasound transducer during swallowing and the compression of the submental region, which happened often in other ultrasound studies.

Penget $\mathrm{al}^{5}$ showed that the CST allows for a better intraindividual reproducibility of the swallowing pattern and for a more standardized and objective ultrasound examination than the hand-held transducer skin coupling scanning technique.

FatemahEzoddini Ardakani ${ }^{6}$ evaluated the swallowing patterns of the tongue using the video-based ultrasound scanning, the B-mode sonography with CST. It was concluded that the B-mode sonography, is a non-invasive procedure permitting direct visualization of the movements of the tongue in both coronal and sagittal planes and can be used with certainity for diagnosing swallowing abnormalities. Quantitative data was not analyzed in this study.

Penget $\mathrm{al}^{7}$ used M mode ultrasonography with CST to evaluate the motion pattern and activity duration of tongue dorsum during swallowing. They concluded that M-mode ultrasonography provides valid information on tongue movements without any side effects and is thus a useful tool in the diagnosis and research of tongue functions in orthodontics and dentistry.

The study by Yabunaka etal $^{8}$ concluded that $\mathrm{B}+\mathrm{M}$ mode imaging provides a simple, noninvasive technique for visual assessment of lateral pterygoid muscle wall and may provide a clinical method to evaluate swallowing. 
Chia-Fen Cheng et $\mathrm{al}^{2}$ used $\mathrm{B}+\mathrm{M}$ mode ultrasonography for qualitative and quantitative evaluation of tongue functions. They concluded that the computer aided B-mode plus M-mode ultrasonography in combination with the CST is a valuable tool for study of tongue functions and relationship between tongue movements during swallowing and dentofacial morphology. This technique was also recommended as a valuable tool for differential diagnosis and etiological studies of tongue dysfunctions, biofeedback training during myofunctional therapy, understanding the physiology of swallowing and speech, and related research.

In the present study we have used the B+M mode sonography aided by the cushion scanning technique (CST) adopted from Chia-Fen Cheng et al to study the tongue movements during habitual or wet swallowing. It offers quantitative and qualitative data for a digital assessment of tongue movement. It gives a time-amplitude diagram for a better understanding of the dynamics of the entire tongue during swallowing. In our study, we found that CST with B+M-mode ultrasonography provides a better visualization and interpretation of tongue movements. Unlike the results of the study by Galen et $\mathrm{al}^{9}$, we observed good intraindividual reproducibility thus making interindividual comparison meaningful.

The results of this study suggest that the individuals with class III skeletal pattern (prognathic mandible) have prolonged duration of tongue movement and greater motion magnitude in the early final phase (IIIA) of swallowing. Though there is a decrease in the motion magnitude and duration of swallowing in the early final phase in the individuals with class II skeletal pattern, the difference between the class I and class II skeletal pattern was not found to be statistically significant. There is no significant difference in the speed of swallowing between the three skeletal patterns. From the bar diagram it is clearly evident that a negative correlation exists between the tongue movement in the motion magnitude of the early final phase (III a) and the intermaxillaryantero-posterior relationship measured using ANB angle and Wit's appraisal. The findings support the studies of Cheng et $\mathrm{al}^{2}$, Ardakani ${ }^{6}$ and Hopkins et $\mathrm{al}^{10}$. Hopkins et $\mathrm{al}^{10}$ studied the position of the mandible and concluded that its anteroposterior position relative to the maxilla and its length are the key factors in determining the level of the tongue relative to the maxillary arch. The findings of Cheng et $\mathrm{al}^{2}$ show that the intermaxillaryanteroposterior relationship including ANB angle and Wits appraisal, has a negative correlation with tongue movement in the motion magnitude of the early final phase (III a). The findings of Ardakani ${ }^{6}$ show the majority of abnormal or inconsistent swallowing patterns in cases of mandibular prognathism.

In this study we have found that there is more correlation between abnormal tongue function during swallowing and class III skeletal pattern than class I and class II skeletal patterns.

Despite the significant increase in the motion magnitude and duration of swallowing [in early final phase] in class III individuals than the other two skeletal patterns, we cannot conclude that abnormal swallowing would cause mandibular prognathism or that the abnormal tongue movements are merely adaptations to the mandibular prognathism. In this case in addition to heredity, many factors must be considered like the frequency of swallowing or how often the tongue exerts force on the teeth, the counteraction of these forces by other muscular structures such as lips, the resistance of dentoalveolar structures to displacement, and the resting posture of the tongue when no swallowing is occurring.

The study did not identify a specific cause-and-effect relationship. The question whether the facial form affects tongue function or vice-versa still remains unsolved. Further studies are needed to understand the traits about form and function. The future scope of the present study could be focused on the cause and effect relationship of tongue function and facial form, such as changes of tongue movement before and after correction of mandibular prognathism or the alteration of occlusion after myofunctional therapy.

\section{Conclusion}

The motion magnitude, duration and speed of the tongue movement during swallowing in the three types of malocclusion are studied using the computer aided B+M mode ultrasonography with the cushion scanning technique. The relationship between the tongue movement and the facial morphology was assessed. The study has corroborated the following findings:

1. The individuals with class III skeletal pattern (prognathic mandible) have prolonged duration of tongue movement and greater motion magnitude in the early final phase (III A) of swallowing.

2. Though there is a decrease in the motion magnitude and duration of swallowing in the

individuals with class II skeletal pattern, the difference between the class II and class I skeletal pattern was not found to be statistically significant.

3. There is no significant difference in the speed of swallowing between the three skeletal patterns.

4. More correlation was found to exist between abnormal tongue function during swallowing and class III skeletal pattern than the class I and class II skeletal patterns. 


\section{References}

[1]. Graber TM. Removable orthodontic appliances. 1984; Philadelphia; London; Toronto: W.B. Saunders

[2]. Cheng CF, Peng CL, Chiou HY and Tsai CY. Dentofacial morphology and tongue function during swallowing. Am J OrthodDentofacialOrthop. 2002 Nov; 122(5):491-9.

[3]. Akiyoshi M, Suzuki S, Kawamura M, Terashima T, Noguchi K, Kuroda T. Study on the tongue movement and the tongue palate relation in deglutition J Jpn.Orthod.Soc. 1995:54: 102-11.

[4]. Shawker TH, Sonies B, Hall TE, Baum BF. Ultrasound analysis of tongue, hyoid, and larynx activity during swallowing. Invest Radiol. 1984 Apr;19(2):82-6.

[5]. Peng CL, Jost-Brinkmann PG, Miethke RR. The cushion scanning technique: a method of dynamic tongue sonography and its comparison with the transducer-skin coupling scanning technique during swallowing. AcadRadiol. 1996 Mar;3(3):239-44.

[6]. Ardakani FE. Evaluation of Swallowing Patterns of the Tongue Using Real-time B-mode Sonography.J Contemp Dent Pract. 2006 Jul 1;7(3):67-74.

[7]. Peng CL, Miethke RR, Pong SJ, Lin CT. Investigation of Tongue Movements during Swallowing with M-Mode Ultrasonography. J OrofacOrthop. 2007 Jan 1; 68(1):17-25.

[8]. Yabunaka K, Konishi $\mathrm{H}$ et al. Ultrasonographic evaluation of geniohyoid muscle movement during swallowing: a study on healthy adults of various ages. RadiolPhys Technol. 2012 Jan 1;5(1):34-9.

[9]. Galén S, Jost-Brinkmann PDP G. B-mode and M-mode Ultrasonography of Tongue Movements during Swallowing. J OrofacOrthop. 2010 Mar 1;71(2):125-35.

[10]. Hopkin GB. Neonatal and adult tongue dimensions. Angle Orthod. 1967 Apr;37(2):132-3.

[11]. Melsen B, Attina L, Santuari M, Attina A. Relationships between Swallowing Pattern, Mode of respiration, and Development of Malocclusion. Angle Orthod. 1987 Apr 1;57(2):113-20.

[12]. Chi-Fishman G, Stone M. A new application for electropalatography: Swallowing. Dysphagia. 1996 Sep 1;11(4):239-47.

[13]. Toshimichi I, Reiko T. Relationship between the lingual-palatal contact during associated with swallowing and maxillofacial morphology with the use of electropalatography. Am J OrthodDentofacialOrthop, 2004: 126:464-76.

[14]. Roehm EG. Computed tomographic measurement of tongue volume relative to its surrounding space.Am $\mathrm{J}$ Orthod. 1982;81(2):172-172.

[15]. Peng CL, Jost-Brinkmann PG, et al. Differential diagnosis between infantile and mature swallowing with ultrasonography. Eur J Orthod. 2003 Oct $1 ; 25(5): 451-6$.

[16]. Peng CL, Jost-Brinkmann PG, et al. Comparison of tongue functions between mature and tongue-thrust swallowing-an ultrasound investigation. Am J OrthodDentofacialOrthop. 2004 May; 125(5):562-70.

[17]. Peng CL, Jost-Brinkmann PG et al. Ultrasonographic measurement of tongue movement during swallowing. JUM. 2000 Jan $1 ; 19(1): 15-20$.

[18]. Wein BB, Drobnitzky M, Klajman S, Angerstein W. Evaluation of functional positions of tongue and soft palate with MR imaging: initial clinical results. J MagnReson Imaging. 1991 Jun;1(3):381-3.

[19]. Lauder R, Muhl ZF. Estimation of tongue volume from magnetic resonance imaging. Angle Orthod. 1991;61(3):175-84.

[20]. Gilbert RJ, Daftary S, Campbell TA, Weisskoff RM. Patterns of lingual tissue deformation associated with bolus containment and propulsion during deglutition as determined by echo-planar MRI. J MagnReson Imaging. 1998; 8(3):554-60.

[21]. Akin E, Sayin MÖ, Karaçay Ş, Bulakbaşi N. Real-time balanced turbo field echo cine-magnetic resonance imaging evaluation of tongue movements during deglutition in subjects with anterior open bite. Am J OrthodDentofacialOrthop. 2006 Jan;129(1):24-8.

[22]. Hartl DM, Albiter M, Kolb F, Luboinski B, Sigal R. Morphologic Parameters of Normal Swallowing Events Using Single-Shot Fast Spin Echo Dynamic MRI. Dysphagia. 2003 Oct 1;18(4):255-62. 